\title{
Design Of Sierpinski Gasket Multiband Fractal Antenna For Wireless Applications
}

\author{
Amanpreet Kaur ${ }^{1}$, Nitin Saluja ${ }^{2}$, J S Ubhi ${ }^{3}$ \\ ${ }^{123}$ Department of Electronics and Communication Engineering \\ ${ }^{13}$ S.L.I.E.T, Longowal ; ${ }^{2}$ Lingaya's University, Faridabad
}

\begin{abstract}
The multiband behavior of the Fractal Sierpinski Gasket Antenna is described in this paper. An analysis is performed to examine the parameters of an antenna with a frequency range in between $1 \mathrm{GHz}$ to 6 GHz. The behaviors of an antenna are investigated such as return loss and bandwidth. Simulations have been done by using different iterations. This multiband Fractal antenna is also used for different wireless applications. Sierpinski gasket antenna using a coplanar waveguide (CPW) feed which is proposed for multiband applications.
\end{abstract}

Keywords: Fractal antenna, CPW feeding, multiband, Sierpinski gasket,

\section{Introduction}

The Sierpinski Gasket (also known as Sierpinski Triangle) was described by Waclaw Sierpinski in 1915, and it became an important sample of Fractal set. The objective of this paper is to be design and simulate Sierpinski gasket Fractal antenna. The behavior and properties of an antenna are investigated. The interaction of electromagnetic waves with Fractal bodies has been recently studied [1] - [7]. The construction of many ideal Fractal shapes is usually carried out by applying an infinite number of times an iterative algorithm such as the multiple reduction copy machine (MRCM) algorithm [8]. In such iterative procedure, an initial structure called generator is replicated many times at different scales, positions and directions, to grow the final Fractal structure. Fractal's antennas are widely preferred for wireless communication systems as they are of small size, light weight, low profile, low cost, and are easy to fabricate and assemble [9]. The Sierpinski triangle geometry drew the attention of researchers as it is smaller than other patch geometries [10]. In this paper CPW feeding technique is used. The design of Sierpinski starts with an equilateral triangle with an operating frequency in between $1 \mathrm{GHz}$ to $6 \mathrm{GHz}$ at various iterations. Four different iterations of triangular patch are compared in terms of their return loss and bandwidths.

\section{Antenna Design}

An equilateral (gasket) triangle patch antenna may be designed by following procedure which assumes that the specified information includes the dielectric constant of the substrate, height of the substrate. Sierpinski gasket antenna is a representative Fractal antenna. Usually, it is inverse triangle configuration 1/2 side triangle of $2 \sqrt{3} \mathrm{~cm}$ of its length of each side of the triangle, when it's zero iteration. The dimension of the substrate is $40 \mathrm{~mm} \times 40 \mathrm{~mm}$. The material used for this design is $\mathrm{FR}_{4}$ with dielectric constant (4.4), thickness of the substrate is 1.59 and loss tangent (0.02). The feeding technique ysed for this design is CPW.

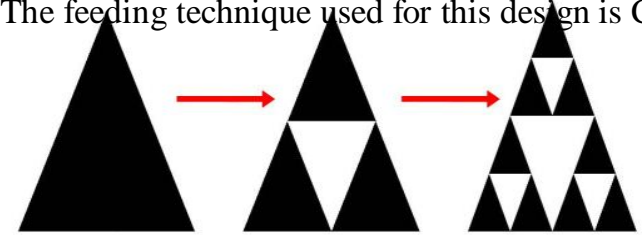

Figure 1. shows a Sierpinski triangle for zero, first and second iteration

\section{Simulation Results}

\subsection{Return loss characteristics}

The plot shows the simulation results of zero iteration. The triangle patch resonates at the frequency band $3.88 \mathrm{GHz}$ having bandwidth $288 \mathrm{MHz}$ with a return loss of $-36 \mathrm{~dB}$ which is quite good. 


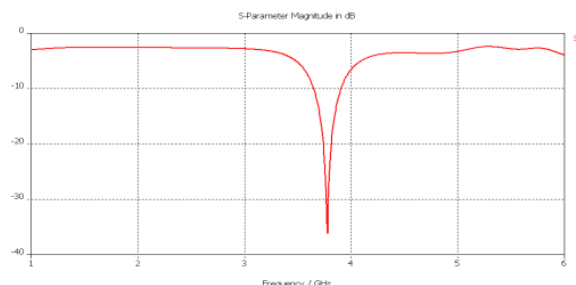

The figure shows the simulation results of the first iteration. The triangle patch resonates at the two frequency bands one is at $3.2 \mathrm{GHz}$ having bandwidth $172 \mathrm{MHz}$ with a return loss of $-23.8 \mathrm{~dB}$ and second at $5.8 \mathrm{GHz}$ having bandwidth $368 \mathrm{MHz}$ with return loss $-23.7 \mathrm{~dB}$ and these are covered WIMAX applications.

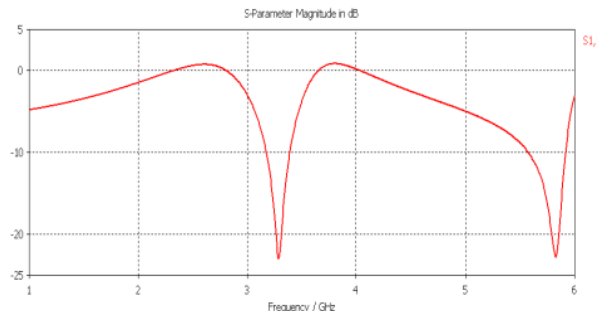

The figure shows the simulation results of the second iteration. This triangle patch resonates at different frequency bands i.e. $2.5 \mathrm{GHz}$ has bandwidth $339 \mathrm{MHz}$ with a return loss of $-17 \mathrm{~dB}, 3.5 \mathrm{GHz}$ has bandwidth $633 \mathrm{MHz}$ with return loss $-16.2 \mathrm{~dB}$ and $5.2 \mathrm{GHz}$ has a bandwidth $143 \mathrm{MHz}$ with return loss $-16.3 \mathrm{~dB}$ and these are covered WIMAX applications.

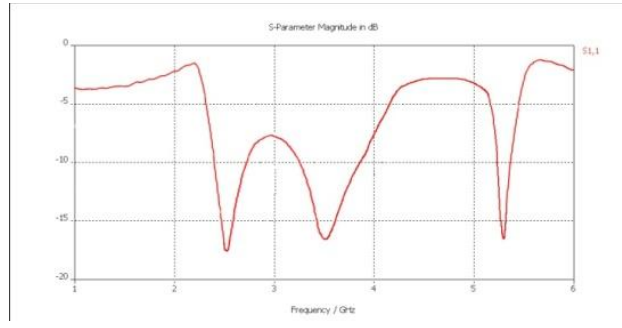

\section{Conclusion}

From result and discussion, it can be concluded that the self similarity in the structure for the 2nd iteration Sierpinski Gasket Fractal antenna is observed to possess multiband behavior. These multiband Sierpinski gasket antenna can cover the frequency bands of WLAN/WIMAX applications. Furthermore, as the no. of iterations increases number of resonant frequencies which gives a multiband performance to the designed antenna structures. The simulated results indicate that the antennas exhibit a good return loss, and multiband frequencies suitable for IEEE Bluetooth/WLAN (2.4-2.484 GHz), WiMAX (3.4-3.69 GHz) \& WIFI (5.1-5.825 $\mathrm{GHz}$ ) wireless communication applications.

\section{References}

[1] D L. Jaggard, “On Fractal electrodynamics,” in Recent Advances in Electromagnetic Theory, H. N. Kritikos and D. L. Jaggard, Eds. New York: Springer-Verlag, 1990, pp. 183-224.

[2] M. Waqas, Z. Ahmad and M.Ihsan, "Multiband Sierpinski Fractal Antenna", in 13th IEEE International Multitopic Conference, 2009, pp. 1-6

[3] G.F. Tsachtsiris, C.F. Soras, M.P. Karaboikis, and V.T. Makios, "Analysis of a Modified Sierpinski Gasket Monopole Antenna Printed on Dual Band Wireless Devices", IEEE Transactions on Antennas and Propagation, vol. 52, no. 10, pp. 2571-2579, October 2004.

[4] L. Lizzi and G. Oliveri, “ Hybrid design of a Fractal-Shaped GSM/UMTS Antenna," J. Of Electromagnetics Waves and Applications, vol. 24, pp. 707-719, 2010.

[5] C. Puente, J. Romeu, R. Pous, X. Garcia and F. Benitez, "Fractal multiband antenna based on the Sierpinski gasket", Electronic Letters, vol. 32, no. 1, pp. 1-2, 1996.

[6] C. Baliarda, J. Romeu, R. Pous, A. Cardama, "On the behavior of the Sierpinski multiband Fractal antenna", IEEE Transactions on Antennas and Propagation, vol. 46, no. 4, pp. 517-524, April 1998.

[7] S. T. Fang, "Analysis and design of triangular microstrip antennas", Ph.D. Dissertation, Department of Electrical Engineering, National Sun Yat-Sen University, Kaohsiung, Taiwan, 1999.

[8] Thomas M. Tirpak, Sam M. Daniel, John D. Lalonde, and Wayne J. Davis, "A Note On A Fractal Architecture For Modeling And Controlling Flexible Manufacturing Systems", IEEE Transactions On Systems, Man, And Cybernetics, Vol. 22, No. 3, May-June 1992.

[9] R Garg, P. Bhartia, I. Bahl, and A. Ittipiboon, Microstrip Antenna Design Handbook, Artech House, Norwood, MA, 2001.

[10] H. R Hassani, D. Mirshekar-Syahkal, "Analysis of triangular patch antennas including radome effects”, Proceedings H Microwaves, Antennas and Propagation, vol. 139, no. 3, pp. 251 - 256, June 1992. 